\title{
CUAVA InGaAs-based, Short Wavelength InfraRed (SWIR) instrument for atmospheric reconnaissance: preliminary design
}

Naif Alsalem, Christopher Betters, Sergio Leon-Saval, Iver Cairns

Naif Alsalem, Christopher Betters, Sergio Leon-Saval, Iver H. Cairns, "CUAVA InGaAs-based, Short Wavelength InfraRed (SWIR) instrument for atmospheric reconnaissance: preliminary design," Proc. SPIE 11852, International Conference on Space Optics - ICSO 2020, 118526A (11 June 2021); doi: 10.1117/12.2600239

SPIE Event: International Conference on Space Optics - ICSO 2021, 2021, Online Only 


\section{International Conference on Space Optics-ICSO 2020}

Virtual Conference

30 March-2 April 2021

Edited by Bruno Cugny, Zoran Sodnik, and Nikos Karafolas
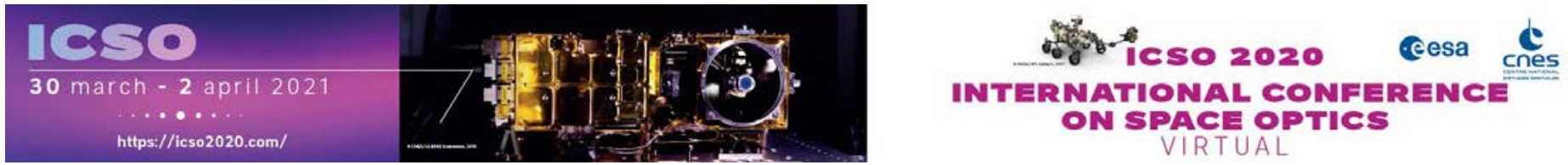

\section{CUAVA InGaAs-based, Short Wavelength InfraRed (SWIR) instrument for atmospheric reconnaissance: preliminary design}

\section{Cesa issopocestings lecnes}




\title{
CUAVA InGaAs-based, Short Wavelength Infrared (SWIR) Instrument for Atmospheric Reconnaissance_Preliminary Design
}

\author{
Naif Alsalem ${ }^{*, a, d}$, Christopher Betters ${ }^{\mathrm{a}, \mathrm{b}, \mathrm{c}, \mathrm{d}}$, Sergio Leon-Saval ${ }^{\mathrm{a}, \mathrm{b}, \mathrm{c}, \mathrm{d}}$, Iver H. Cairns ${ }^{\mathrm{a}, \mathrm{d}}$ \\ a ARC Training Centre for CubeSats, UAVs \& Their Applications (CUAVA), University of \\ Sydney, Sydney, NSW 2006, Australia; b Sydney Astrophotonic Instrumentation Laboratory (SAIL), \\ University of Sydney, Sydney, NSW 2006, Australia; ' Sydney Institute for Astronomy (SIfA),

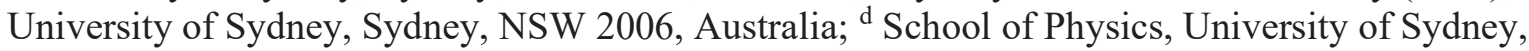 \\ NSW 2006, Australia.
}

\begin{abstract}
We report the preliminary design of a new small-size remote sensing instrument operating in the Short Wavelength Infrared (SWIR) domain of the spectrum $(1.588 \mu \mathrm{m}$ to $1.673 \mu \mathrm{m})$ to monitor, detect, and measure atmospheric constituents such as Carbon Dioxide $\left(\mathrm{CO}_{2}\right)$ and Methane $\left(\mathrm{CH}_{4}\right)$ concentrations. We highlight the instrument features, technical specifications (including a relatively high spectral resolution of approximately $0.4 \mathrm{~nm}$ ), optical design, and components. The instrument's synthetic spectral response is also explored using NASA's Planetary Spectrum Generator (PSG), a Line-by-law radiative transfer code. The instrument is currently under development at the ARC Training Centre for CubeSats, UAVs \& Their Applications (CUAVA), and Sydney Astrophotonic Instrumentation Laboratory (SAIL) at the University of Sydney. Once built, it will conduct an atmospheric reconnaissance from an Unmanned Aerial Vehicle (UAV) and will be tested to qualify for future space flights on one of CUAVA's CubeSats.
\end{abstract}

Keywords: SWIR, NIR, Atmospheric Monitoring, Spectrometer, InGaAs Detector, Remote Sensing.

\section{INTRODUCTION}

Atmospheric composition has been a continuous target for both long- and short-term studies and analysis due to its critical role in life developing and surviving on Earth ${ }^{1,2}$. The chemical composition of Earth's atmosphere, in particular, has attracted wide attention from both the atmospheric and space physics community in detecting, measuring, and quantifying atmospheric molecules and suspended particles. Atmospheric molecules such as Carbone Dioxide $\left(\mathrm{CO}_{2}\right)$, Methane $\left(\mathrm{CH}_{4}\right)$, Water Vapor $\left(\mathrm{H}_{2} \mathrm{O}\right)$, Carbone Monoxide (CO), and Nitrous Oxide $\left(\mathrm{N}_{2} \mathrm{O}\right)$ are of particular interest to atmospheric physicists due to their roles in trapping heat in the atmospheric layers ${ }^{3}$, leading to what is known as global warming ${ }^{4-6}$.

There have been various instruments designed and developed to enable air- and space-based measurements of atmospheric gases. They can be summarized in two categories: 1) Large instruments with super high spectral resolution and 2) Small instrument with coarse spectral resolutions. Space missions such as Orbiting Carbon Observatory-2 (OCO-2 $)^{7}$, Greenhouse Gases Observing Satellite (GOSAT) ${ }^{8}$, SCanning Imaging Absorption spectroMeter for Atmospheric CHartographY $(\text { SCIAMACHY) })^{9}$, and Carbon Dioxide Observation Satellite Mission (TanSat) ${ }^{10}$ were built with large and custom-made optics and detectors. Their design approach was developed to enable ultra-high spectral resolutions $(0.08 \mathrm{~nm}-0.16 \mathrm{~nm})$ from space-based platforms, leading to an expensive budget allocation. On the other hand, small instruments on Nanosatellites such as Argus 1000 micro-spectrometer onboard the second Canadian Advanced Nanospace eXperiment satellite $(\mathrm{CanX}-2)^{11}$ enables miniaturization concepts but comes with coarse spectral resolution $(5 \mathrm{~nm})$ compared to large spacebased instruments. The Greenhouse Gases Satellite (GHGSat), however, is another NanoSat that carries a passive spectrometer with a relatively high spectral resolution $(0.1 \mathrm{~nm})^{12}$ but is tuned only to detect the atmospheric Methane $\left(\mathrm{CH}_{4}\right)$ concentration in the narrow spectral channel $1630-1675 \mathrm{~nm}^{13}$.

*naif.alsalem@sydney.edu.au 
In this paper, we report a small-size, cost-effective instrument that utilizes commercial off-the-shelf components (COTS), i.e., optical elements such as Infrared lenses, and operates in the spectral interval $1.588 \mu \mathrm{m}-1.673 \mu \mathrm{m}$ with a relatively high spectral resolution of approximately $0.4 \mathrm{~nm}$. The instrument will have the capability to detect and measure $\mathrm{CO}_{2}$ and $\mathrm{CH}_{4}$ absorption bands simultaneously from an Unmanned Aerial Vehicle (UAV) platform, and will be tested to qualify for a space mission onboard one of CUAVA's NanoSats in the near future.

\section{INSTRUMENT}

\subsection{Optical Design}

The instrument is a passive spectrometer operating in the Short Wavelength Infrared (SWIR) part of the spectrum from $1.588 \mu \mathrm{m}$ to $1.673 \mu \mathrm{m}$. It is intended to conduct the first atmospheric reconnaissance from a UAV platform and be tested to qualify for a future space mission. The instrument specifications are listed in Table 1.

The optical layout of the instrument was designed using OpticStudio ${ }^{\circledR}$ ZEMAX software which enables optical simulation. The Instrument optical design mainly consists of five optical elements, slit, collimator, diffraction grating, camera (focusing unit), and detector. Figure 1 shows the instrument's preliminary optical layout produced by Zemax.

Table 1: Instrument parameters

\begin{tabular}{|l|l|}
\hline Parameter & Value \\
\hline Spectral Range & $1.588 \mu \mathrm{m}-1.673 \mu \mathrm{m}(1588 \mathrm{~nm}-1673 \mathrm{~nm})$ \\
\hline Spectral Resolution & $0.4 \mathrm{~nm}$ \\
\hline Detector & $640(\mathrm{~W}) \times 512(\mathrm{~L})$ pixels \\
\hline Diffraction Grating & $6001 / \mathrm{mm}($ VPH Transmission Grating) \\
\hline Littrow angle & $29^{\circ}$ \\
\hline Slit & $25 \mu \mathrm{m}(\mathrm{W}) \times 3 \mathrm{~mm}(\mathrm{~L})$ \\
\hline
\end{tabular}

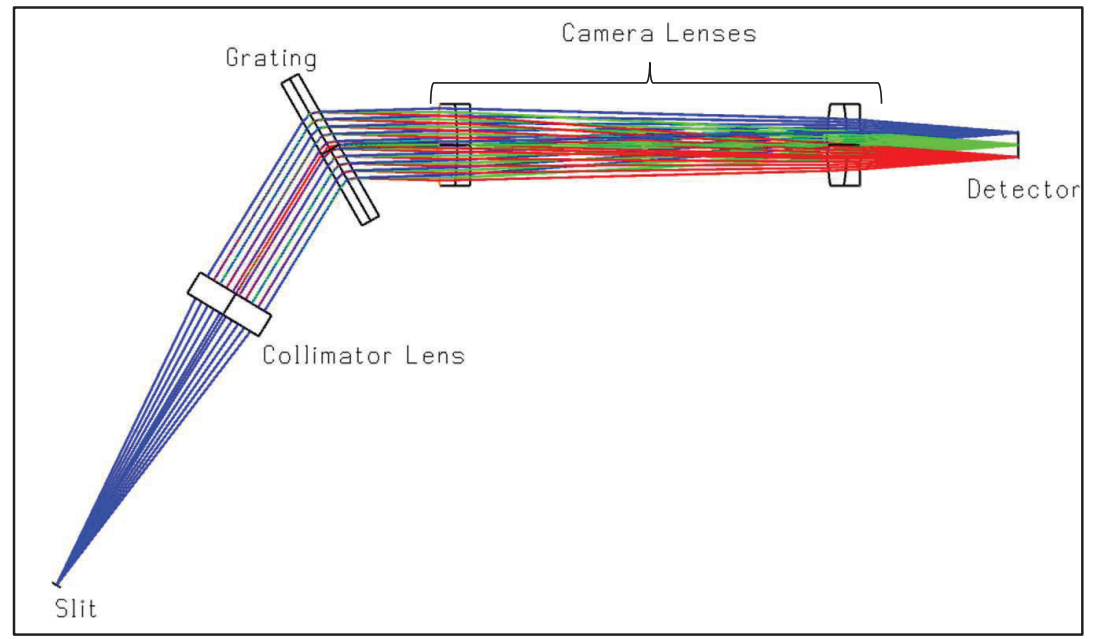

Figure 1: Instrument Optical Layout. Colors represent the wavelengths where Blue is the minimum of $1.588 \mu \mathrm{m}$, Green is the central wavelength $1.6305 \mu \mathrm{m}$, and Red is the maximum wavelength of $1.673 \mu \mathrm{m}$. 


\subsubsection{Input Slit}

Etendue is a significant quantity that defines the amount of light collected by the instrument, and it must be matched for all the optical components in the instrument ${ }^{14}$. The following equation describes it as:

$$
E=A \Omega
$$

where A is the area of the slit surface and $\Omega$ is the solid angle at which light is accepted into the instrument.

It is acknowledged that there must be a trade-off between the slit size and the spectral resolution of the instrument to maintain a high signal-to-noise ratio (SNR) with acceptable spectral resolution.

In this instrument, light is collected by a conventional field lens, which must have an F/\# of 3.3, and will pass through a $25 \mu \mathrm{m}$ slit width that has a length of $3 \mathrm{~mm}$. Figure 2 shows the slit simulation in Zemax. The slit is positioned perpendicular on the transmission grating to enable Littrow condition with an angle of $29^{\circ}$.

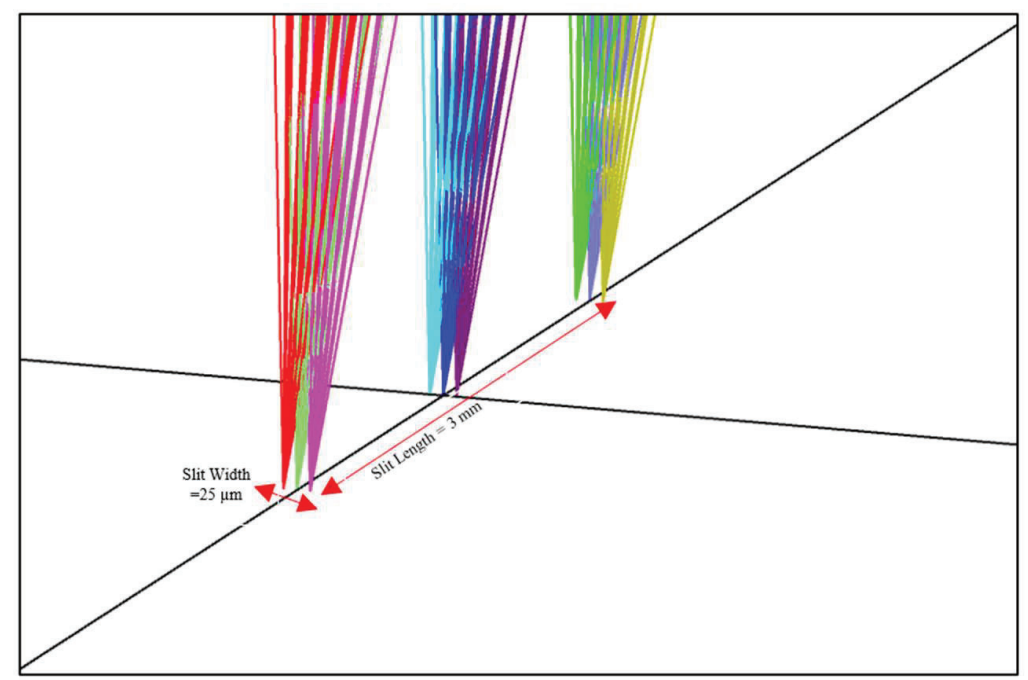

Figure 2: A close-up look at the slit. Slit length is $3 \mathrm{~mm}$, while the width is $25 \mu \mathrm{m}(0.025 \mathrm{~mm})$. The rectangular slit is simulated to model the light at three different positions in the rectangular. On-axes positions are shown in the middle at three points, one at the centre and two at the edges. Off-axes positions are shown at the two extreme ends of the rectangular slit.

\subsubsection{The Collimator, Grating, and Camera}

We have experimented with a wide variety of lenses available in Zemax libraries from different manufacturers, e.g., ThorLabs, Edmund Optics, and Newport, and found preliminary suitable optical components for the system. Starting with the collimator, we have selected an achromatic lens coated for the Near Infrared (NIR) and Short Wavelength Infrared (SWIR) bands from Edmund Optics ${ }^{\mathrm{a}}$. It has a diameter of $30 \mathrm{~mm}$, an effective focal length of $100 \mathrm{~mm}$, and thus an $F / \#$ of approximately 3.33. It is shown in Figure 1 as a white rectangle with no further details because the manufacturer only provided a ZEMAX Blackbox of this lens to preserve their intellectual property rights. The collimated light will illuminate a transmission grating (Wasatch Photonics ${ }^{b}$ ) with a $600 \mathrm{line} / \mathrm{mm}$ with a diameter of $50.8 \mathrm{~mm}$, which is oriented in a Littrow configuration with an incident angle of $29^{\circ}$. The diffraction grating offers an average efficiency of up to $90 \%$ at $1.588 \mu \mathrm{m}$. It, however, drops to approximately $86 \%$ at $1.673 \mu \mathrm{m}$, as shown in Figure 3. Diffracted light will then be brought into a focal point at the detector using two achromatic lenses (Edmund Optics) with a diameter of $25 \mathrm{~mm}$. The camera lenses have focal lengths of $200 \mathrm{~mm}$ and $150 \mathrm{~mm}$, respectively, and are separated by a distance of about $108.5 \mathrm{~mm}$ resulting in a total effective focal length of $47.9 \mathrm{~mm}$.

a https://www.edmundoptics.com

$\mathrm{b} \underline{\mathrm{https}: / / \text { wasatchphotonics.com }}$ 


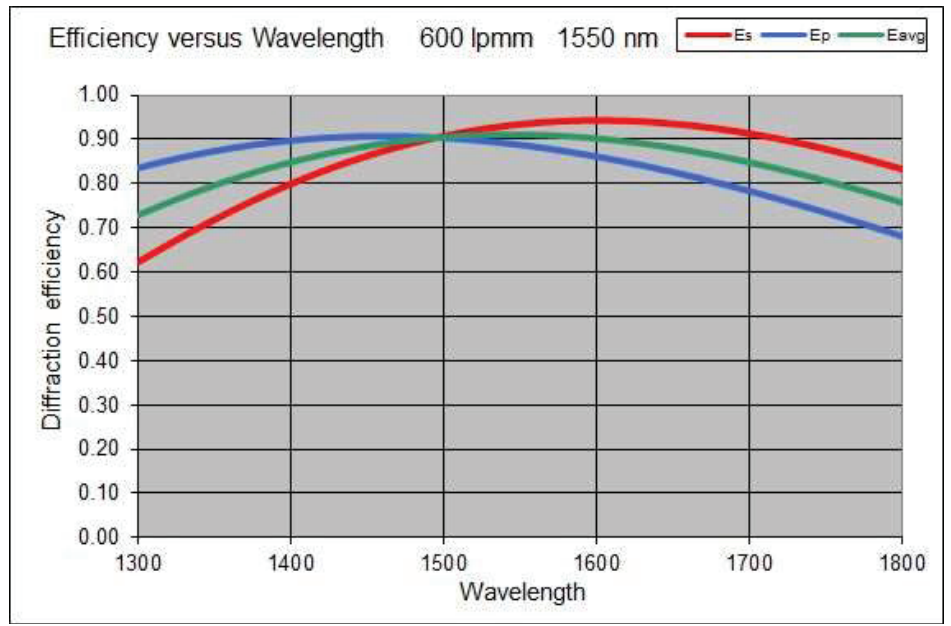

Figure 3: Typical transmission grating efficiency specified by Wasatch Photonics The efficiency of S- and P-type polarized light are shown in red and blue lines, respectively. The average efficiency is shown in the green line. Figure credit: (C) 2021 Wasatch Photonics.

\subsubsection{Detector}

An Indium Gallium Arsenide (InGaAs) based detector is a perfect candidate in the SWIR range for its compactness, high Quantum Efficiency $(\mathrm{QE})^{15}$ and being the most cost-effective option we have. We aim to employ a high-speed, $640 \times 512$ pixels detector with a QE of approximately 70\% from the First Light Imaging. It has a length and width of $55 \mathrm{~mm}$ and a pixel pitch of $15 \mu \mathrm{m}$ resulting in an active area that fully accommodates all wavelengths, as shown in Figure 4.

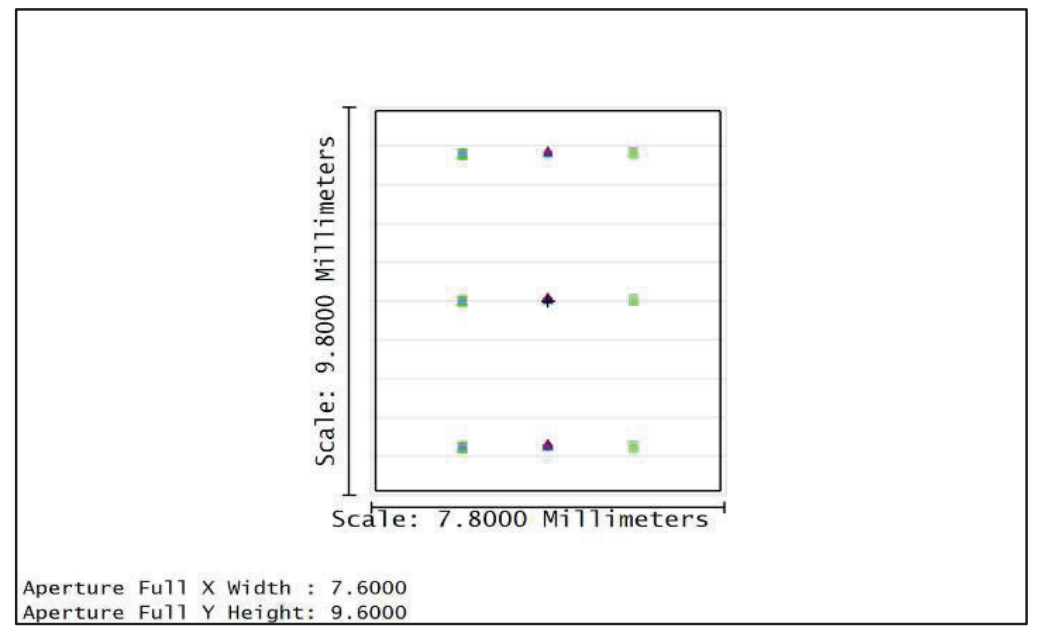

Figure 4: Footprint diagram of the image on the detector. The aperture's full $\mathrm{Y}$ height is $9.6 \mathrm{~mm}$, representing the 640 pixels. The $\mathrm{X}$ width of the aperture $(7.6 \mathrm{~mm})$ represents the 512 pixels on the detector. 


\section{PERFORMANCE}

\subsection{ZEMAX Simulation}

The slit is modelled by selecting nine positions (fields), 3 in the middle, 3 in the right, and 3 in the left, as shown in Figure 2. The initial system performance was tested by ray tracing and generating the Spot Diagram of each field position for a range of wavelength, as shown in Figure 6. The columns represent the minimum, central and maximum wavelengths with a spectral step (resolution) of $0.4 \mathrm{~nm}$. The system's minimum wavelength, $1588 \mathrm{~nm}$, is shown in group A and advanced with a spectral step of $0.4 \mathrm{~nm}$ twice, giving $1588.4 \mathrm{~nm}$ and $1588.8 \mathrm{~nm}$ shown in the second and third columns, respectively. The central and maximum wavelengths, $1630.5 \mathrm{~nm}$ and $1673 \mathrm{~nm}$ are shown in group B and C, respectively, with the same spectral step. The filed positions on the slit are shown in the rows. Group 1 has three positions at the center of the slit. Group 2 and 3 show another 3 points at the right and left edges of the slit, respectively. The spot diagram shows that all rays are confined within the Airy disk with a radius of $12.14 \mu \mathrm{m}$. It is also noteworthy that the spot diagram illustrates a relatively consistent and uniform performance of the system on and off-axis.

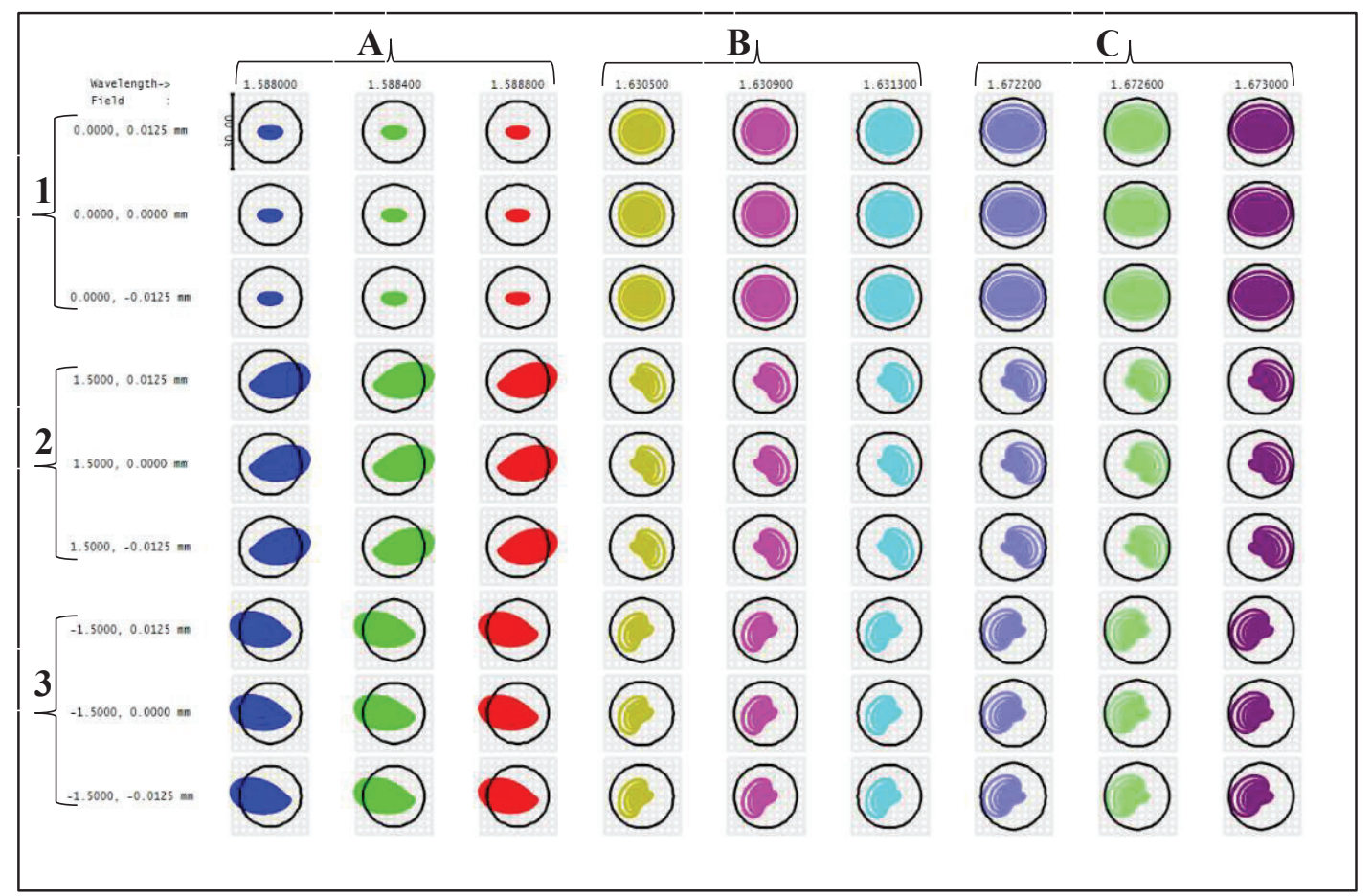

Figure 56: Matrix Spot Diagram of filed positions in slit shown in Figure 2. Columns show the wavelengths $1588 \mathrm{~nm}, 1630.5 \mathrm{~nm}$, and $1673 \mathrm{~nm}$ with a spectral step of $0.4 \mathrm{~nm}$. Rows represent positions selected on the slit center and the two extreme edges. The box size is $30 \mu \mathrm{m}$, and the Numerical Aperture (NA) is 0.1 .

The system's spectral resolution was tested in ZEMAX by generating the Geometric Image Analysis (GIA) feature, which we use to show the wavelengths separated by the required spectral step can be resolved. Figure 7 shows the central wavelength of $1630.5 \mathrm{~nm}$ with two adjacent wavelengths, $1630.9 \mathrm{~nm}$ and $1631.3 \mathrm{~nm}$, separated by $0.4 \mathrm{~nm}$ spectral step. The normalized radiance profiles of these wavelengths' peaks are shown in Figure 8. The Full-Width-at-Half-Maximum (FWHM) value in figure 8 indicates that the slit image is sampled by at least 2 pixels on the detector. 


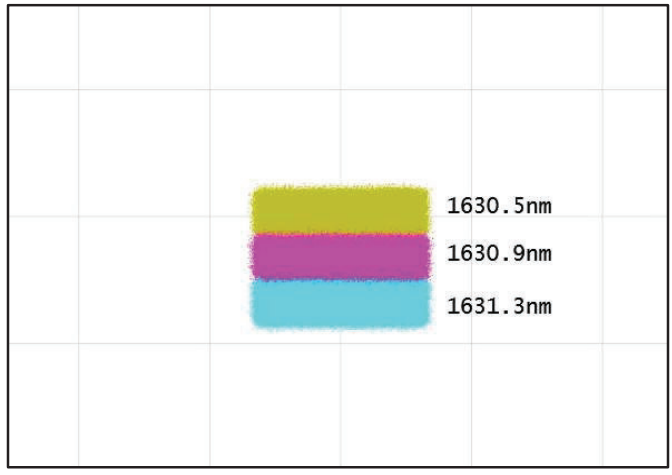

Figure 67: Central wavelength $1630.5 \mathrm{~nm}$ with two nearby wavelengths, $1630.9 \mathrm{~nm}$, and $1631.3 \mathrm{~nm}$, separated by $0.4 \mathrm{~nm}$.

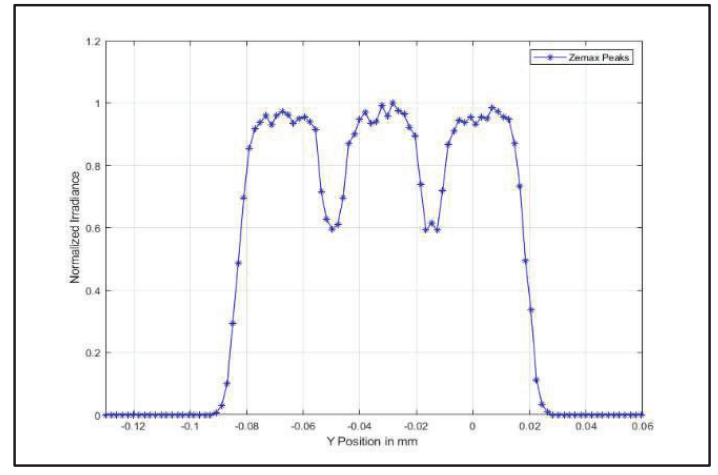

Figure 78: Normalized Radiance profile of the wavelengths peaks in figure 6

\section{SPECTRAL ANALYSIS}

\subsection{Synthetic Spectral Responsivity}

The instrument operates in the SWIR interval $1.588 \mu \mathrm{m}-1.673 \mu \mathrm{m}$, which includes some atmospheric molecular absorption bands, mainly $\mathrm{CO}_{2}, \mathrm{CH}_{4}$ and $\mathrm{H}_{2} \mathrm{O}$. This spectral domain offers minimal interference by $\mathrm{H}_{2} \mathrm{O}$ and relatively high signal-to-noise ratio (SNR) compared to thermal channels. The solar radiance that reflects off the ground and travels back to space carries various information about the atmosphere that can be inferred, i.e., gas concentration, temperature, and pressure. The Planetary Spectrum Generator (PSG) ${ }^{16}$ is an online accurate radiative transfer code developed to solve the entire atmosphere's radiative transfer equation. It allows the user to enter all the parameters related to Earth, atmosphere, and instrument. Thus, it has been used to simulate our instrument's spectral range, where data is stored and processed in MATLAB. Figure 9 shows the instrument spectral range that includes absorption bands of $\mathrm{CO}_{2}$ and $\mathrm{CH}_{4}$. Figure 10 shows the gas transmittance in the instrument spectral window. The main atmospheric and spectroscopic parameters used in this Line-by-Line calculation are listed in Table 2.

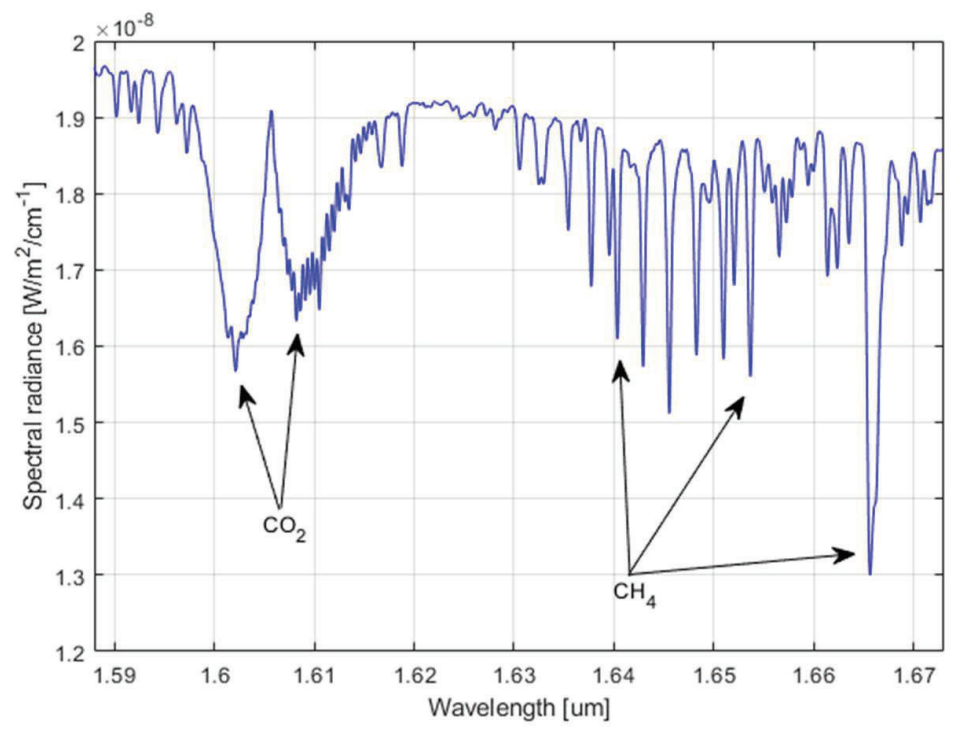

Figure 89 : Instrument spectral interval generated by NASA's Planetary Spectrum Generator (PSG). The lines resolution is set to 0.4 $\mathrm{nm}$ to simulate the instrument spectral resolution. 


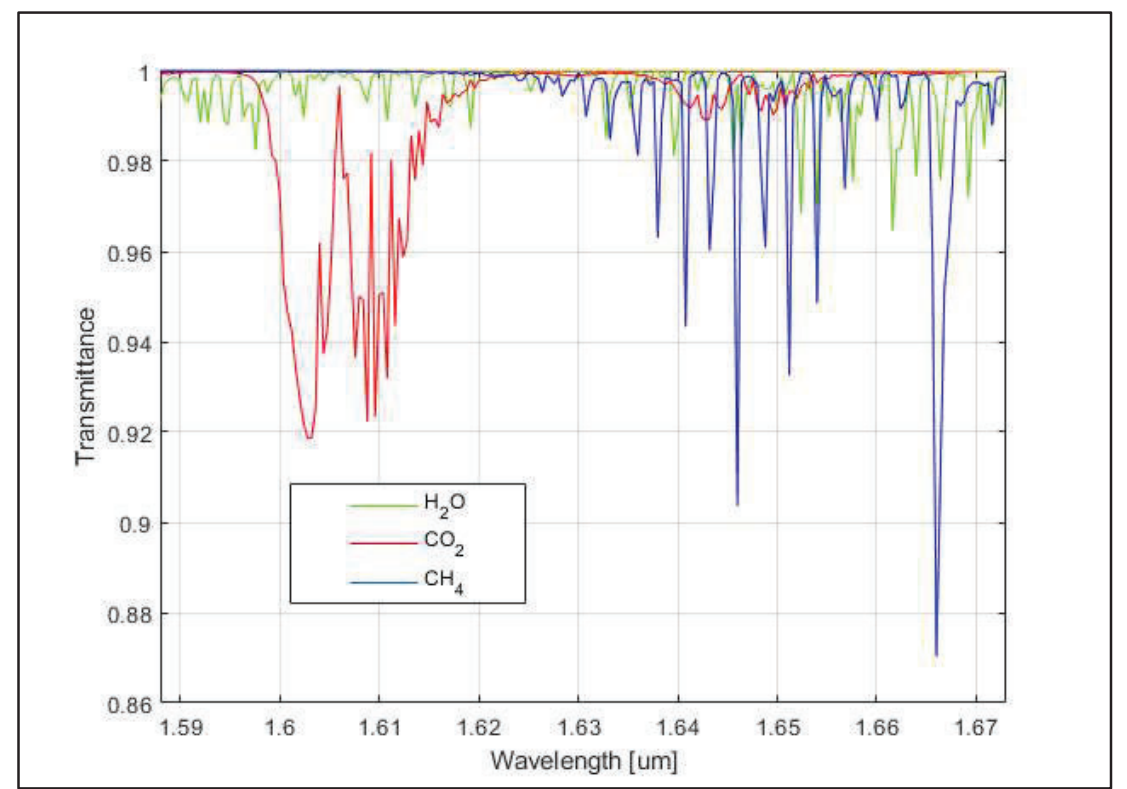

Figure 910: Gases transmission in the atmosphere. $\mathrm{CO}_{2}$ (red) $\mathrm{CH}_{4}$ (blue), and $\mathrm{H}_{2} \mathrm{O}$ (green), profiles are plotted with standard concentrations in the atmosphere.

Table 2: Calculation parameters used to solve the Radiative Transfer Equation in the synthetic atmosphere.

\begin{tabular}{|l|l|}
\hline Parameter & Value \\
\hline Atmospheric model & Hydrostatic Equilibrium \\
\hline Spectroscopic Information & HiTRAN 2016. \\
\hline Albedo & 0.31 \\
\hline Surface Temperature & $296.54 \mathrm{~K}$ \\
\hline Spectral Range & $1.588 \mu \mathrm{m}-1.673 \mu \mathrm{m}$ \\
\hline Spectral Resolution & $0.4 \mathrm{~nm}\left(1.58 \mathrm{~cm}^{-1}\right)$ \\
\hline Observation Geometry & Nadir \\
\hline Observation angle & $31^{\circ}$ \\
\hline Incidence angle: & $51.519^{\circ}$ \\
\hline
\end{tabular}

\subsection{Retrieval Algorithm}

The challenges of retrieving atmospheric constituents from space \& aircraft (including UAVs)-based platforms are well known to the Atmospheric and Space physics community. However, much effort has been put into developing retrieval algorithms to meet various mission's needs ${ }^{17-22}$. These algorithms share a basic fundamental approach that requires forward modelling, but each employs different inversion techniques to infer the atmospheric parameters of interest. The inversion algorithms offer a significant mean to infer specific components from the radiative transfer equation, which is not invertible analytically because of its non-linearity nature.

The adapted retrieval method for the instrument is similar, in concept, to that of OCO-2 ${ }^{18}$, GOSAT ${ }^{21}$, and SCIAMACHY ${ }^{19,20}$ missions retrievals where the algorithm starts with a forward model that includes instrument parameters to generate a synthetic measurement and ends by employing an inversion method, Optimal Estimation ${ }^{23}$, to infer the 
atmospheric parameters of interest. Furthermore, the Levenberg-Marquardt inversion algorithm ${ }^{24}$ will be evaluated once the flight data is ready for analysis. The forward model can be mathematically represented by the measurement vector, $\mathbf{y}$ as follows:

$$
\mathbf{y}=\mathbf{F}(\mathbf{b}, \mathbf{c}, \mathbf{x})+\varepsilon
$$

Equation 2 states that the spectrum (e.g., measurement) $\mathbf{y}$ is a function (F )of the parameters, b for the instrument parameters, $\mathbf{c}$ for the known physical parameters, and $\mathbf{x}$ for is the state vector of the target (e.g., the atmospheric gas of interest). The $\varepsilon$ term represents the noise or random error in the set of measurements ${ }^{25}$.

As mentioned previously, to inverse the equation, an iterative retrieval algorithm based on Bayesian optimal estimation ${ }^{23}$ will be employed. Bayes's rule finds the probability of a specific event by combining a priori knowledge about the atmospheric state to obtain the posterior state. Bayes's theorem can be implemented, assuming Gaussian statistical distribution, in the retrieval algorithm and the maximum posterior probability state $\hat{\mathbf{x}}$ and its covariance matrix $\widehat{\mathbf{S}}$ are:

$$
\begin{aligned}
& x^{2}=(\mathbf{y}-\mathbf{F}(\mathbf{x}))^{T} \mathbf{S}_{\varepsilon}^{-1}(\mathbf{y}-\mathbf{F}(\mathbf{x}))+\left(\mathbf{x}-\mathbf{x}_{a}\right)^{T} \mathbf{S}_{a}^{-1}\left(\mathbf{x}-\mathbf{x}_{a}\right) \\
& \mathbf{S}=\left(\mathbf{K}^{T} \mathbf{S}_{\varepsilon} \mathbf{K}+\mathbf{S}_{a}^{-1}\right)^{-1}
\end{aligned}
$$

where the $\mathbf{x}$ and $\mathbf{y}$ are the state vector and measured spectrum, respectively, illustrated in Eq. (2), $\mathbf{S}_{\varepsilon}$ is the measured error covariance, $\mathbf{x}_{a}$ and $\mathbf{S}_{a}$ are the priori state vector and priori covariance matrix, $\mathrm{T}$ is the transpose operator, $\mathbf{K}$ is the weighting function $^{18}$ and $\mathbf{F}(\mathbf{x})$ is the forward model expressed in Eq. (2).

\section{CONCLUSION}

We have reported a new small size, passive remote sensing instrument operating in the Short Wavelength Infrared (SWIR) with a relatively high spectral resolution of approximately $0.4 \mathrm{~nm}$ to monitor, detect and measure $\mathrm{CO}_{2}$ and $\mathrm{CH}_{4}$ concentration in the lower atmosphere. We have shown the instrument preliminary optical design and performance in ZEMAX and simulated its spectral responsivity utilizing the Planetary Spectrum Generator (PSG), a line-by-line radiative transfer code developed by NASA. The filed lens, which determines the field of view (FOV), will be selected, and the whole system will be tested again in ZEMAX. Initially, the instrument will conduct its first reconnaissance from a UAV platform and collect data over various targets on the ground. It will, then, be tested to qualify for a space mission onboard one of CUAVA's future CubeSats.

\section{REFERENCES}

[1] Harrison RM, Jones M. The chemical composition of airborne particles in the UK atmosphere. Science of the Total Environment. 1995;168(3):195-214.

[2] Hashimoto GL, Abe Y, Sugita S. The chemical composition of the early terrestrial atmosphere: Formation of a reducing atmosphere from CI-like material. Journal of Geophysical Research: Planets. 2007;112(E5).

[3] Ramanathan V, Feng Y. Air pollution, greenhouse gases and climate change: Global and regional perspectives. Atmospheric environment. 2009;43(1):37-50.

[4] Anderson TR, Hawkins E, Jones PD. CO2, the greenhouse effect and global warming: from the pioneering work of Arrhenius and Callendar to today's Earth System Models. Endeavour. 2016;40(3):178-187.

[5] Dickinson RE, Cicerone RJ. Future global warming from atmospheric trace gases. Nature. 1986;319(6049):109-115. 
[6] Lashof DA, Ahuja DR. Relative contributions of greenhouse gas emissions to global warming. Nature. 1990;344(6266):529-531.

[7] Eldering A, Wennberg PO, Viatte C, Frankenberg C, Roehl CM, Wunch D. The Orbiting Carbon Observatory-2: First 18 months of science data products. Atmospheric Measurement Techniques. 2017;10(2):549-563.

[8] Hamazaki T, Kaneko Y, Kuze A, Kondo K. Fourier transform spectrometer for greenhouse gases observing satellite (GOSAT). Paper presented at: Enabling sensor and platform technologies for spaceborne remote sensing2005.

[9] Bovensmann H, Buchwitz M, Frerick J, et al. SCIAMACHY on ENVISAT: In-flight optical performance and first results. Paper presented at: Remote Sensing of Clouds and the Atmosphere VIII2004.

[10] Bi Y, Yang Z, Gu S, Wang Q, Gao L, Chen J. Impacts of aerosol and albedo on TanSat CO2 retrieval using the near infrared $\mathrm{CO} 2$ bands. Paper presented at: Remote Sensing of the Atmosphere, Clouds, and Precipitation V2014.

[11] Alsalem N, Tsouvaltsidis C, Roberts C, Quine B. Clouds effect on the atmospheric total column carbon dioxide retrieval by space orbiting Argus 1000 micro-spectrometer: introductory study. Paper presented at: Remote Sensing of the Atmosphere, Clouds, and Precipitation VII2018.

[12] Varon DJ, Jacob DJ, McKeever J, et al. Quantifying methane point sources from fine-scale satellite observations of atmospheric methane plumes. Atmospheric Measurement Techniques. 2018;11(10).

[13] Jervis D, McKeever J, Durak BO, et al. The GHGSat-D imaging spectrometer. Atmospheric Measurement Techniques Discussions. 2020:1-23.

[14] Betters CH, Leon-Saval SG, Robertson JG, Bland-Hawthorn J. Beating the classical limit: A diffraction-limited spectrograph for an arbitrary input beam. Optics express. 2013;21(22):26103-26112.

[15] Hansen MP, Malchow DS. Overview of SWIR detectors, cameras, and applications. Paper presented at: Thermosense $\mathrm{Xxx} 2008$.

[16] Villanueva GL, Smith MD, Protopapa S, Faggi S, Mandell AM. Planetary Spectrum Generator: An accurate online radiative transfer suite for atmospheres, comets, small bodies and exoplanets. Journal of Quantitative Spectroscopy and Radiative Transfer. 2018;217:86-104.

[17] Crisp D, Fisher B, O'Dell C, et al. The ACOS CO2 retrieval algorithm-Part II: Global XCO2 data characterization. 2012.

[18] Bösch H, Toon G, Sen B, et al. Space-based near-infrared CO2 measurements: Testing the Orbiting Carbon Observatory retrieval algorithm and validation concept using SCIAMACHY observations over Park Falls, Wisconsin. Journal of Geophysical Research: Atmospheres. 2006;111(D23).

[19] Buchwitz M, Rozanov VV, Burrows JP. A near-infrared optimized DOAS method for the fast global retrieval of atmospheric $\mathrm{CH} 4, \mathrm{CO}, \mathrm{CO} 2, \mathrm{H} 2 \mathrm{O}$, and $\mathrm{N} 2 \mathrm{O}$ total column amounts from SCIAMACHY Envisat-1 nadir radiances. Journal of Geophysical Research: Atmospheres. 2000;105(D12):15231-15245.

[20] Reuter M, Buchwitz M, Schneising O, Heymann J, Bovensmann H, Burrows J. A method for improved SCIAMACHY CO 2 retrieval in the presence of optically thin clouds. Atmospheric Measurement Techniques Discussions. 2009;2(5):2483-2538. 
[21] Yoshida Y, Ota Y, Eguchi N, et al. Retrieval algorithm for $\mathrm{CO} 2$ and $\mathrm{CH} 4$ column abundances from short-wavelength infrared spectral observations by the Greenhouse gases observing satellite. Atmospheric Measurement Techniques. 2011;4(4):717.

[22] Reuter M, Bösch H, Bovensmann H, et al. A joint effort to deliver satellite retrieved atmospheric $\mathrm{CO} 2$ concentrations for surface flux inversions: the ensemble median algorithm EMMA. Atmospheric Chemistry \& Physics. 2013;13(4).

[23] Rodgers CD. Inverse methods for atmospheric sounding: theory and practice. Vol 2: World scientific; 2000.

[24] Moré JJ. The Levenberg-Marquardt algorithm: implementation and theory. In: Numerical analysis. Springer; 1978:105-116.

[25] Woodhouse I. Thirteen short chapters on Remote Sensing. In: University of Edinburgh; 2016. 